\section{Abstractions}

\section{SOLE AUTHOR}

A brainstorming session with her colleagues at NASA's Marshall Space Flight Center in Huntsville, Alabama, inspired Feryal Özel and helped her produce the paper on page 1115 of this issue. An astrophysicist at the University of Arizona in Tucson, Özel was looking in to the relationship between the mass and radius of neutron stars. The crucial data came from $X$-ray satellites monitor ing a burst of $X$-rays from a neutron star. As a result, Özel was able to derive equations that should allow researchers to determine the mass and radius of neutron stars simultaneously. Özel tells Nature about the journey from her native Turkey to the farthest reaches of the Universe

Why did you switch from particle physics to astrophysics early in your career? In part because I realized that things in particle physics occur on timescales that just don't match my person ality. Hoping that whatever theory you work on will be tested in ten years if the right instruments are constructed was nots omething that went with my more impatient nature. But in astrophysics, therewas a data boom. There were alot of interesting physics questions thatcould be answered right then and there.

Are theremore options now for young scientists than when you grew up in Turkey? The past five or six years have seen the es tablishment of the first privateuniversities. They now have some physics, engineering, even astrophysics positions. When students in Turkey ask me what they should do, I tell them that they can go far beingin Turkey. But the academic environment that the United States provides still cannot bematched. If they want to be one of the top scientists, I think it's necessary to have at least some exposure outside Turkey.

How confident are you about the equations?

You can't imagine the number of e-mails I've already received about that. People are either fascinated by them or they're asking 'Why are you using these data?' or 'How can you trust that formula?'. It's an amazing reaction and the paper isn't even out yet. I'm perfectly confidentin themethod. But the data for surecan be improved.

Do you have concems about astrophysics given recent funding trends at NASA? I' $m$ wor ried that NASA is in decline. The science fund ing is going down, future missions are being cut. There is a lot more emphasis on defence-related and engineering-related programmes than when I first got involved in the field. So there is this overall climate of worry that we're not going to be able to generate anything as exciting in the coming decades because we're simply not planning missions to get the data.
MAKING THE PAPER

\section{Kristin France}

\section{A fresh perspective on biodiversity and the movement of organisms.}

A hundred buckets and some lengths of plastic tubing may not sound like the most high-tech array of equipment, but it's pretty much all Kristin France needs to build ecosystems.

Based at the College of William and Mary in Gloucester Point, Virginia, France created the ecosystems to find out what happened to them when organisms migrated from one area to another. The loss of biodiversity is thought to damage the health and stability of an ecosystem, but few studies have considered the role of migration and immigration in the process, France says.

To find out more, France created a basic marine habitat consisting of sea water and seagrass in each bucket. The water was filtered so that only algae and other microorganisms made it through. The buckets were put in groups of five, giving France 20 'metacommunities.' Within these metacommunities, some of the buckets were connected together with plastic tubing and some were left isolated, so that in some cases organisms would be free to disperse between the buckets. "We wanted to incorporate the processes that create diversity in the real world," says France.

Each bucket was then given 30 tiny crustaceans, which graze on the algae that grow on the seagrass. The actual number of grazer species put in each bucket varied, but overall each metacommunity received either low biodiversity in the shape of three species, or high biodiversity with eight species. France and her labmates spent about two months in the heat, setting up and monitoring the system - one of the reasons "people have not done this kind of experiment", she smiles.

France spent the next six weeks sampling each bucket to see how the ecosystems were changing . It took me about eight months to count and characterize everything under the microscope

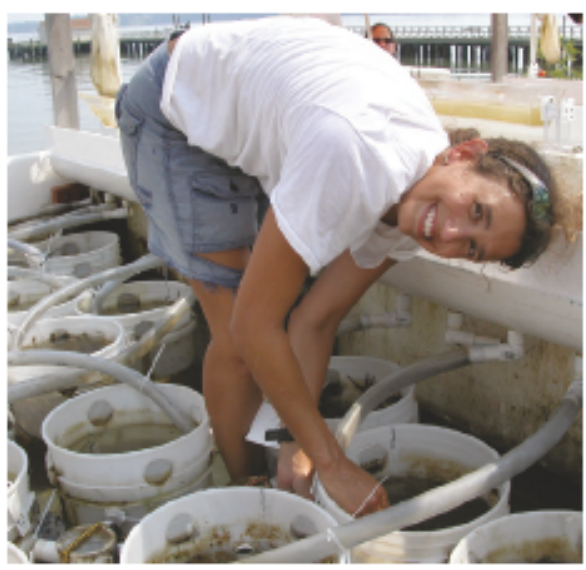

with the help of a fantastic technical assistant," she says. But if the data collection was labourintensive, working out what the data meant was an even bigger challenge. The fruits of that labour appear on page 1139 of this issue.

Earlier studies had indicated that greater biodiversity leads to a more stable ecosystem, but France found that in somecases the opposite was true. Increasing biodiversity often produced greater variability in organisms from bucket to bucket. The only time France saw a stabilizing effect from increased diversity was when she looked at the 'sum' of all the buckets within a metacommunity. "So, in one way, we got the effect that we were expecting, that increasing biodiversity increases stability through time," she says. "But only when we looked at the metacommunity scale" However, this was true only for the isolated buckets - when grazers were allowed to move from bucket to bucket, the stabilizing effect vanished.

The results should help conservationists who are dealing with increasingly fragmented habitats. "It may be that to maintain ecosystem function you have to think about both biodiversity and the level of connectivity in different habitats," France says. "You may not be able to maximize both and also stabilize ecosystem function." France now wants to follow up her work by looking at how well-connected and unconnected communities respond to a disturbance, such as a sudden rise in temperature.

\title{
ON THE WEB PEER-REVIEWDEBATE
}

Six new contributions to Nature's online debate about peer review are published today at www.nature.com/nature/peerreview/debate/ index.html

Systems:Online frontiers of thepeer-reviewed literature

Theodora Bloom

Perspective: The case for group review Debomoy Lahiri

Perspective: Peer review of interdisciplinary scientific papers

Christopher Lee
Quality and value: The true purpose of peer review

Charles Jennings

Quality and value: Models of quality control for scientific research

Tom Jefferson

Ethics: Trust and reputation on the web William Arms

Readers are invited to join the debate in Nature's peer-review comments blog at: http://blogs.nature.com/nature/peerreview/ debate/comments 